\title{
INTELLECTUAL ENTREPRENEURSHIP AS CAPITALIZATION OF KNOWLEDGE IN INNOVATIVE ENVIRONMENTS AND PATTERNS OF ITS EMERGENCE
}

\author{
Irina Sennikova ${ }^{1}$
}

\begin{abstract}
This paper presents the results of an exploratory study into the phenomenon of intellectual entrepreneurship and the patterns of its emergence as understood through the experience of individuals. The research is of qualitative nature, and the results are based on secondary research and interviews of 16 intellectual entrepreneurs of Latvia. It provides a model of intellectual entrepreneurship, which is defined as capitalization of knowledge in an innovative environment. It also presents four patterns of emergence of intellectual entrepreneurship in Latvia; these include patterns characteristic of a transition period from command to a free market economy and that occurring during times of crises, and ones relevant to a stable economic environment. The paper contributes to the modern theory of entrepreneurship where the concept of intellectual entrepreneurship is used, but with different interpretations, and until recently had not been systematically studied.
\end{abstract}

JEL Classification Numbers: L26, O300, DOI: http://dx.doi.org/10.12955/cbup.v4.750

Keywords: intellectual entrepreneurship, entrepreneurship, knowledge capitalization.

\section{Introduction}

This paper investigates the phenomenon of intellectual entrepreneurship in one of the post-Soviet countries, Latvia, which underwent a major change process from a socialist to a capitalist economy and then onto becoming a full member of the European union in 2004. Reforms to transform the economy over that time established Latvia as the fastest growing economy in Europe, enjoying 7\% annual economic growth, and being labeled the 'Baltic Tiger'. However, this period of triumph did not last. When the global economic and financial crisis hit the global economy in 2008, Latvia suffered the most of all European countries, in losing almost twenty per cent of its economy (Central Statistical Bureau of Latvia, 2016). Current economic and geopolitical trends show that turbulent times are likely to continue and the future of economic prosperity is unclear. Experiencing the challenging times of the transformation was traumatic for Latvians. Managers of large state enterprises found it difficult to adapt to the new competitive environment and were unable to effectively use either their existing productive resources or their established economic relationships.

At the same time, many state enterprises struggled, while other sources of economic activity emerged. Individual entrepreneurs who were able to adapt to the new era formed companies, generally with low levels of capital investment. Many of the individuals were professionally or scientifically qualified, but were mostly without any formal management education or experience. They created companies, not because of restructuring processes, but based on their intellectual abilities, previous experience, and intuitive understanding of economics and entrepreneurship. Having established their companies at the beginning of the 1990s they managed to survive the turbulence of the global economic crisis and develop companies regardless of the unfavorable economic environment. This raises the question as to whether or not these were instances of intellectual entrepreneurship and if so, how did these emerge as such.

\section{Studies Addressing the Problem}

The term, intellectual entrepreneurship (IE), is relatively new, but has been used since, at least, the mid nineteen nineties (Chia, 1996). Authors in several countries have discussed intellectual entrepreneurship, although there is no common understanding of the term. Until recently, there have been two major sources of publications devoted to the phenomenon. One is from the Kozminski University in Warsaw, where in 1998 the UNESCO Chair in Intellectual Entrepreneurship was established. Since then, there has been a stream of annual publications collating research in Intellectual Entrepreneurship and related areas from different geographic regions (Kwiatkowski, 1999, 2001a, 2001b; Stowe, 1999, 2001; Gold, 2003; Edvinsson, 2003; Kirpalani \& Nowak 2004). The other source is the University of Texas, Austin, which offers a structured graduate program in intellectual

\footnotetext{
${ }^{1}$ Irina Sennikova, RISEBA University, Riga, Latvia, irina.sennikova@ riseba.lv
} 
entrepreneurship and whose faculty extensively publishes about this topic (e.g., Cherwitz \& Sullivan, 2002; Cherwitz, 2005, Cherwitz \& Darwin 2005; Beckman \& Cherwitz, 2009). The approaches of these two schools are different. The object of research in the studies published in the series of Knowledge Café for Intellectual Entrepreneurship (1999, 2001, 2003, 2004, 2005), in most cases, is the entrepreneur, a person who is already in business, whereas in the Austin case it is a scholar. At Austin, they believe that IE leverages knowledge for the betterment of society by doing what academic institutions do best, i.e., teaching people to think critically and equipping them with the disciplinary knowledge and tools to keep discovering and learning (Cherwitz \& Darwin 2005). Mavridis (2011) remained in between these two schools of thought, claiming that intellectual entrepreneurship is not (only) about the 'academics', but rather about those who 'think' before, during, and after performing any entrepreneurial activity. Abosede and Onakoya (2013), in their view, believed that intellectual entrepreneurship infers applying rationality and intuition within the learning cycle as well as contextually thinking 'outside the box'. They combined the approaches of the two schools by saying that intellectual entrepreneurship is creating synergistic relationships among disciplines and between the academic and the public and private sectors.

In addition to these two schools, Sweden has largely focused on developing their intellectual potential, and regards itself as a 'showcase for intellectual entrepreneurship', believing that individual brainpower, combined with structural capital of well-established institutions, will generate its future growth (Invest in Sweden Agency, 2005). The Swedish approach, to a great extent, corresponds to the work of Leif Edvinsson (2003), who interrelated intellectual capital entrepreneurship with the wealth of nations.

Although, in recent years, the number of publications on intellectual entrepreneurship has significantly increased, the term is still open to interpretation. Stowe (1999) emphasized the intellectual half of the term by identifying IE as building businesses based on the philosophy of developing an organization with intellectual capital. Some researchers emphasized the entrepreneurship of intellectuals by stressing their 'vital role as economic and social agents of change' (Kwiatkowski, 1999). Representatives of the 'Austin school' refer mainly to academic professionals, while talking about intellectual entrepreneurship and believe that "intellect is not limited to academia, and entrepreneurship is not limited to business" (Cherwitz \& Sullivan, 2002).

Regarding the role of intellectual entrepreneurs in developing the economy, most researchers stress the positive impacts; however, again, they provide no clear set of criteria for defining it. Some researchers argue that intellectual entrepreneurs, through offering better products, processes, systems, or services, will generate wealth for economic prosperity (Sharif, 2004). Others argue that "through participation in different environments, through their openness and criticism, but above all due to the nature of their learning process (beyond double loop), they become contemporary heroes of entrepreneurship" (Kwiatkowski 2001b, p. 158). Stowe (2004) suggested that the extent to which entrepreneurs, and, specifically, intellectual entrepreneurs, contribute to a nation's economy can be estimated by examining the number of new business formations and tax revenues from those new entities. Kirpalani (2003) believed that in today's world of the 'new economy' the role of intellectual entrepreneurship has vaulted to the forefront and warrants especial attention. He insisted that with new economy demands, an intellectual entrepreneur can leave the 'beyond double loop' learning and move from an existing environment that experiences rapid technological change and chaos to help form a new environment. Similarly, Antal (2004) considered that intellectual entrepreneurship will undoubtedly be in great demand in the coming decades and will become a primary source of economic renewal and societal development.

Although these three approaches are different, they represent the framework for further analysis of the phenomenon of intellectual entrepreneurship. They also confirm the suggestion of Johannisson, Kwiatkowski, and Dandridge (1999), concerning the emergence of intellectual entrepreneurship on the basis of intellectualism, entrepreneurship, and academia. They also justify the argument concerning the role of intellectual entrepreneurship in developing the economy and contributing to national wealth creation in the knowledge economy. The value of corporations, organizations, and individuals is directly related to their knowledge and intellectual capital (Edvinsson, 2003). 
Our review of literature on intellectual entrepreneurship revealed the most frequently repeated notions that refer to developing a comprehensive understanding of the phenomenon of intellectual entrepreneurship.

Figure 1: Three dimensions of intellectual entrepreneurship

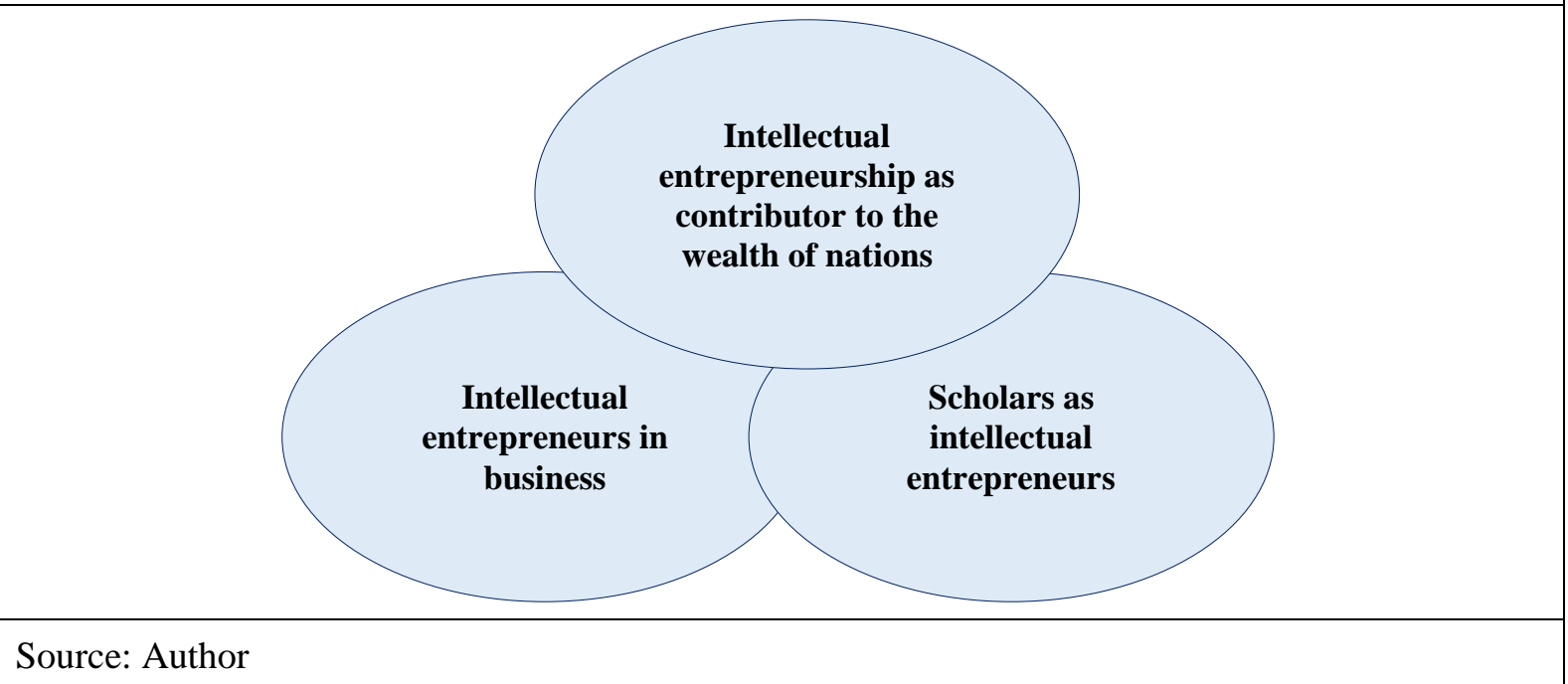

\section{Design and Methods}

As the term intellectual entrepreneurship is still open to interpretation, the main objective of this research is to develop a comprehensive understanding of intellectual entrepreneurship and to identify the patterns of its emergence in Latvia. The research also seeks to explain the reason people from different backgrounds, without having special management education, acquire a business and become successful entrepreneurs.

As the reason for the research is to understand and describe meaningful social activity, the patterns of emerging intellectual entrepreneurship in Latvia, as an interpretive approach towards the methods of inquiry was adopted, as opposed to a positivist or critical social science approach (Neuman, 2003). Because of the novelty of the research area and the nature of the questions asked, as well as the exploratory character of the study, a qualitative approach to the research design and methodology was used. The case study method was chosen as the most appropriate for the current study, with the need for a case study arising out of a desire to understand complex social phenomena (Yin, 2003), which is precisely the case with studying the phenomenon of intellectual entrepreneurship. Further, according to Yin (2003), as a research strategy, case studies are commonly used to contribute knowledge relating to individuals, groups, organizations, society, politics, and related phenomena.

For this research, a multiple case design was adopted. Multiple cases are considered similar to multiple experiments, i.e., they follow a replication rather than a sampling logic (Yin, 2003). Our field research consisted of interviewing 16 entrepreneurs, who represented various industries: information and technology (IT) and communication equipment, chemical manufacturing, telecommunications, social work and education, the beauty industry, network technologies and solutions, textile industry, leisure and hospitality, gambling, software, and the oil transit industry.

\section{Research Results}

\section{Connection Between Intellectualism and Entrepreneurship}

For the purpose of this research, the definition of an intellectual by Etzioni (1968) was used, which defines an intellectual as possessing a diverse knowledge base and, of being critical and unattached. Possession of these characteristics was the criterion for selecting cases for investigation. The main objective of the research was to understand intellectual entrepreneurship, and thus, during interviews research participants were asked to provide their own perceptions of an intellectual and an entrepreneur, and to reflect on the connection between the world of intellectualism and the world of entrepreneurship. 
Figure 2: Perception of an intellectual

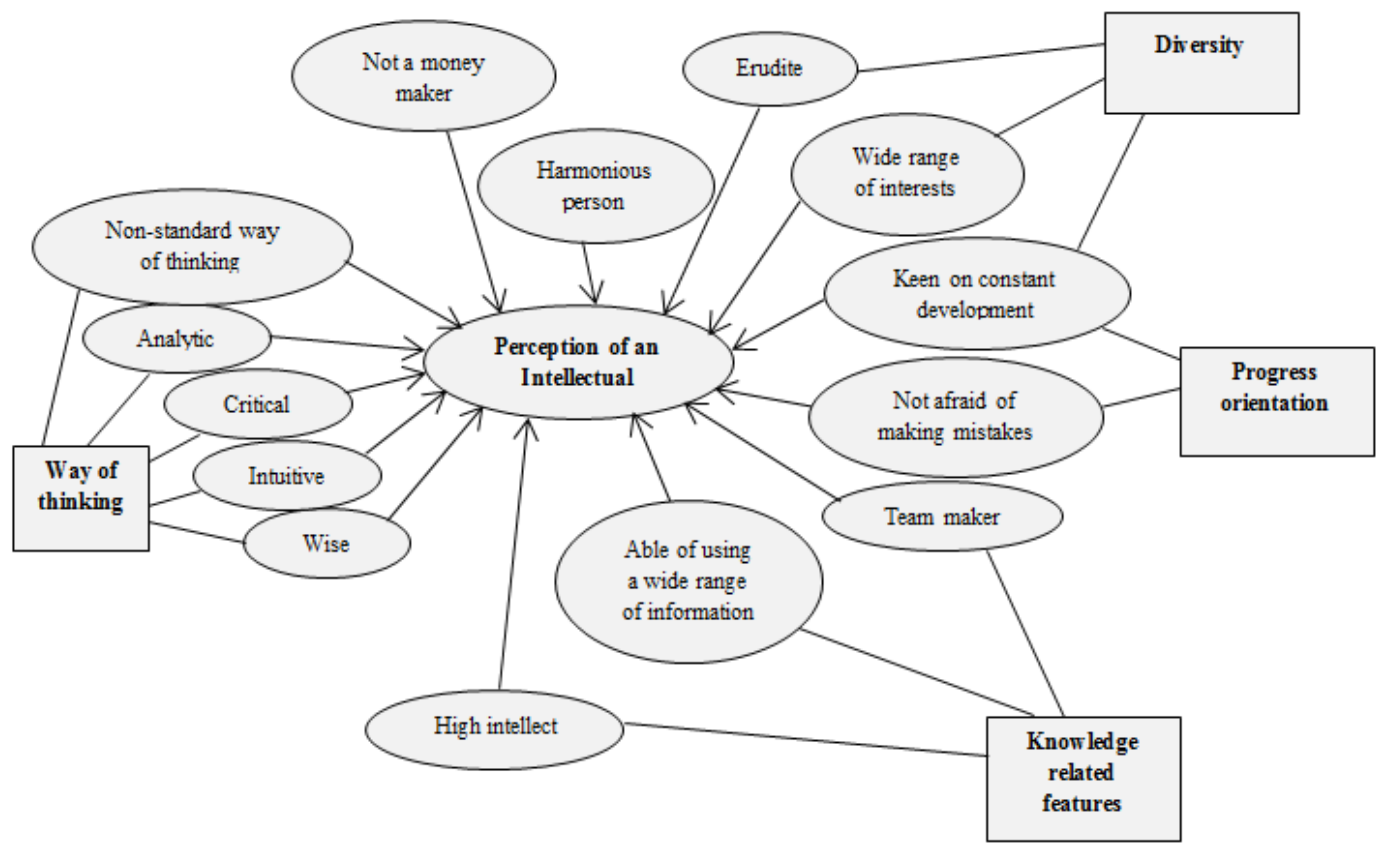

Source: Author

Figure 2 summarizes how the research participants viewed an intellectual. There appears no contradiction between Etzioni's definition and their perception. There was a broadening of the existing definition and consideration from different angles. As shown in Figure 2, an intellectual was characterized by four main groups of attributes:

1. 'personal diversity', an intellectual is a person with wide range of interests, is an erudite, and consequently, is a harmonious person;

2. 'knowledge related', is comprised by attributes like high intellect, ability to use wide range of information sources, being knowledgeable and educated, which does not necessarily presuppose high level of formal education;

3. 'the way of thinking', namely being creative, critical, analytical, and having a non-standard way of thinking. Personal wisdom, which has been mentioned as a feature of an intellectual can also be attributed to this category; and

4. 'orientation to progress', namely being keen on constant development and not afraid of making mistakes, which fosters and facilitates development.

As a standalone feature, the inability of an intellectual to generate income is more of a stereotype rather than a real attribute.

The definition of entrepreneurship for the purpose of this research was adopted from Gartner, Bird and Starr (1992), who emphasized the emergence of (new) business activity as part of the entrepreneurship process. Nevertheless, the personality and attributes of an entrepreneur are also crucial for understanding the phenomenon of intellectual entrepreneurship and as to whether a connection exists between the world of entrepreneurship and the world of intellectualism. Therefore, during the interviews the research participants were asked to provide their views on entrepreneurs. The accumulated perception of an entrepreneur is presented in Figure 3. 
Figure 3: Perception of an entrepreneur

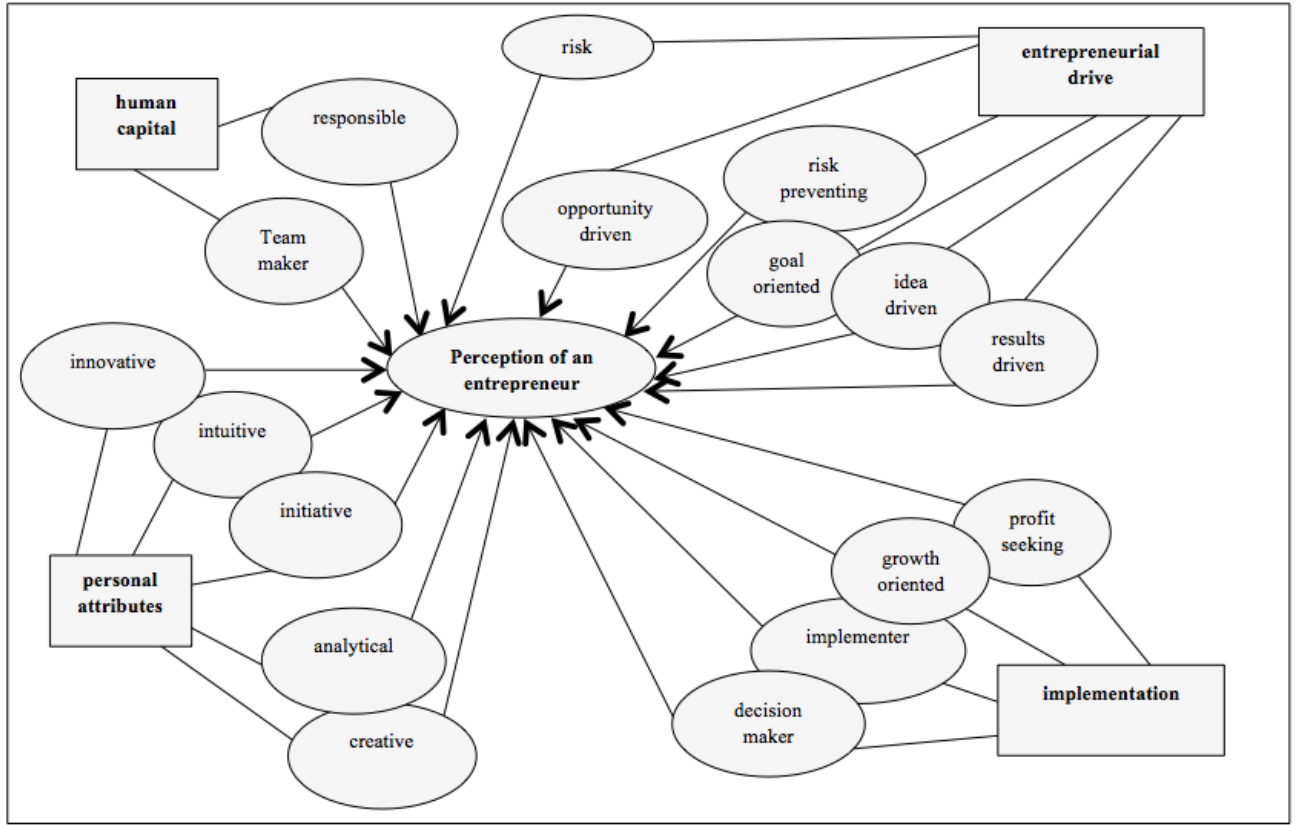

Source: Author

As shown in Figure 3, the perception of an entrepreneur through the eyes of the research participants can be divided into several categories.

One is related to the 'entrepreneurial drive' and encompassing such attributes as being idea, opportunity, and goal driven, and being capable of taking risks for achieving the goal, on one hand, while trying to prevent risk, on the other.

Another group of responses implied 'implementation' or being capable of creating business. This category included perceptions of an entrepreneur, such as, a good decision-maker, able to implement one's ideas and profit from them, as well as not being satisfied with their achievement level and thus, constantly seeking further growth.

A separate category is related to 'human capital' and stresses the ability of an entrepreneur to establish a team and be responsible for its members.

Lastly, but not surprisingly, is a category embracing 'personal attributes' of an entrepreneur, similar to those of an intellectual, namely showing initiative, being intuitive, creative, and innovative, and possessing analytical ability.

A comparison of Figures 2 and 3 shows there were many commonalities between the descriptions of intellectuals and entrepreneurs given by the participants. Figure 4 summarizes the many connections between two seemingly distant worlds, one of intellectualism and the other of entrepreneurialism. The entrepreneurs, the same as the intellectuals, had a wide range of interests that lead to a specific thinking process and developed creativity, innovation and heightened intuition. Both, intellectuals and entrepreneurs think critically of what they would do and are never satisfied with their achievements; they are continually in the development phase. Being driven by results they wish to accomplish, they search for optimum solutions and are capable of making decisions in non-standard situations.

Furthermore, intellectuals feel somewhat comfortable in an entrepreneurial arena. Most intellectuals think that their intellect helps them in business, to 'make it easier'. They assume that being an intellectual will help them regardless of what they are doing. With their thinking and analytic abilities, it is easier to understand business logic. Diverse knowledge and communicability opens opportunities to engage with wider constituencies and to be interesting to different people. It also provides a common language among professionals, and this helps build trust and understanding within 
organizations. However, it also highlights the moral contemplations of intellectuals and that they are more likely aware of social issues and business ethics. This should not be regarded negatively, as social responsibility of businesses is a major concern in today's global market and wider involvement of intellectuals could render business more socially responsible.

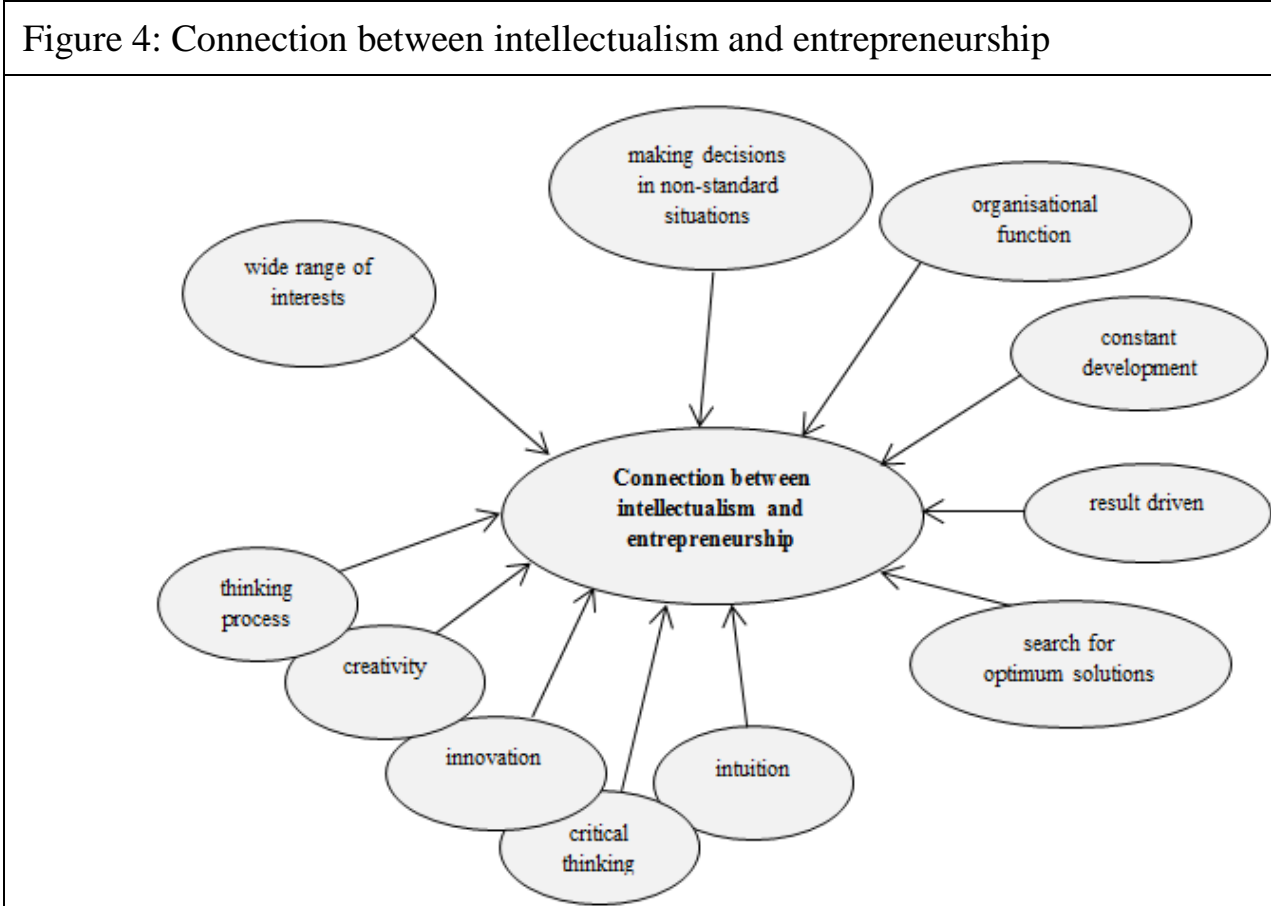

Source: Author

Moreover, intellectuals foresee many challenges and this causes their minds to constantly work and to not 'give up'. These challenges are multifaceted and viewed from different angles. Some relate them to the challenges provided by the market conditions, i.e., competition and strategic choices. Others related them to the constant need for personal development and could see significant challenges in managing human resources. Political challenges were also mentioned, but most probably this thinking reflected the turbulent times and the numerous associated changes of the transition from command to a free market. Reaching goals and setting new ones, thus providing a constant need for business development, were also perceived as intellectual challenges. Moreover, to be able to innovate in noninnovative industries and search for non-standard decisions in standard spheres of entrepreneurship was seen as requiring much creativity and certainly imposing significant challenges. Therefore, it can be concluded that entrepreneurship provides, not less, but possibly more intellectual challenges that tend to attract the relentless cravings of intellectual minds.

It was almost unanimously stated that intellectuals should enter business, as they bring benefits, such as, harmony, inspiration, creativity, and imagination, thus 'making it better' and 'more beautiful' (if you can say so about business). In addition, it was said that intellectuals contribute to the core of business, as they make more competent decisions and foster higher quality management. Also, intellectuals were perceived as a business engine and creators of new knowledge in the modern world.

However, there was also an opinion that intellectuals entered into business as a resulted of the collapse of the old system, with people having to find new ways of living and survival, and this should not occur again.

\section{Defining Intellectual Entrepreneurship}

A conceptual framework (Figure 5) was developed from the review of literature to guide this research. The conceptual framework defined the knowledge economy in the context of either intellectual entrepreneurship or the environment within which it occurs. The assumption of the conceptual framework was that knowledge creation, creativity, innovation, organizational learning, and intellectual human capital are the key interrelated components constituting intellectual 
entrepreneurship. Interpretation of the data collected from the field research validated this initial assumption and highlighted the importance of knowledge, both as a non-material resource and as a basis for constant development and innovation. The role of intellectual capital, as an integral part of intellectual entrepreneurship, was also crystallized during the research. The same concerned the learning, both individual and organizational. Individual learning, both experiential and academic, of intellectual entrepreneurs has contributed to organizational learning and sustains the organizations.

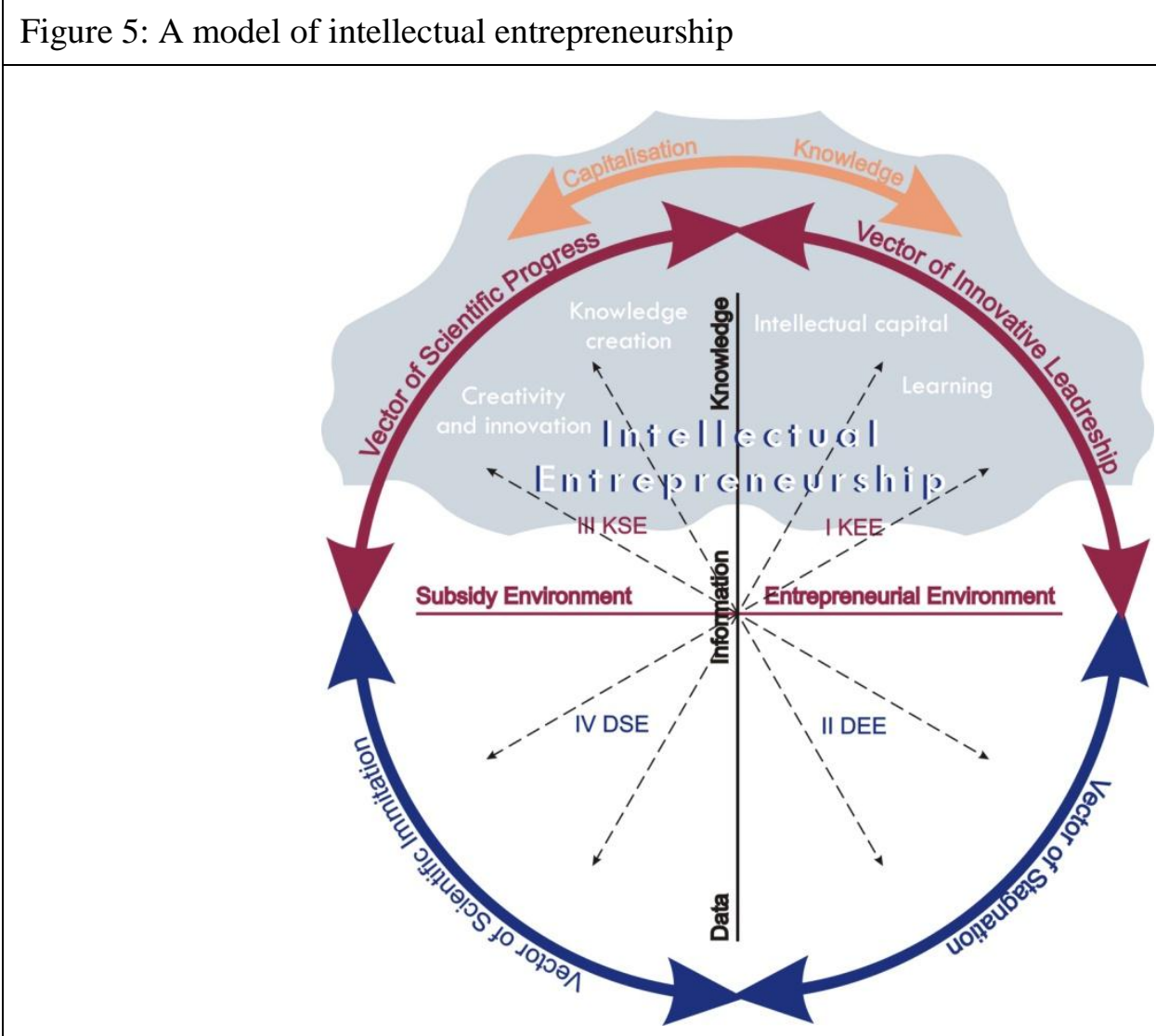

Source: Author

Another idea, from the field research related to knowledge utilization, as knowledge becomes a resource when capitalized into material wealth. A data analysis of the patterns of knowledge utilization was performed. For this purpose, the traditional Data-Information-Knowledge-Wisdom (DIKW) hierarchy (Ackof, 1989) was reviewed. In the modern world of the knowledge economy and information age, the rate of the reverse cycle accelerates when knowledge reverts to information and data, and stops being a competitive advantage. The only way to compete, then, is to constantly innovate and generate new knowledge, and this was recognized as a feature of intellectual entrepreneurship. Based on this premise, a new model was developed featuring the zone of intellectual entrepreneurship.

The developed model is based on the familiar sequence: 'data-information-knowledge', as well as on the environment of knowledge materialization. The model presents four patterns of knowledge capitalization: 1) knowledge of entrepreneurial environment; 2) data of entrepreneurial environment; 3) knowledge of subsidy environment; and 4) data of subsidy environment. Based on the results of this research, it is argued that both entrepreneurial and subsidy environment, when based on knowledge rather than on data, provide an innovative background and a field for intellectual entrepreneurship. The pattern 'knowledge-entrepreneurial environment' gives grounds for innovative leadership and competitive advantage for an organization and the pattern 'knowledge-subsidy environment' ensures scientific progress, as opposed to stagnation in business and imitation in science, when capitalization is based on data or secondary information. 
Based on the developed model, the following definition of intellectual entrepreneurship was developed: 'Intellectual Entrepreneurship is capitalization of knowledge in innovative environment'. The underlying thought for the definition is that knowledge generation and creation of intellectual capital are only possible when constant innovation is taking place; when, as soon as knowledge converts to information, new knowledge needs to be generated and capitalized, so that the company remains competitive.

\section{Patterns of Emergence of Intellectual Entrepreneurship.}

Regarding intellectual entrepreneurship in Latvia, one needs to consider that the country has recently transitioned from a command to a market oriented economy, and therefore the patterns of emerging intellectual entrepreneurship are specific to a transitioned period. However, some emerging patterns are characteristic of a stable economy.

Based on the analysis of empirical data, four emerging patterns of intellectual entrepreneurs were identified.

The first group is called a 'natural' one and the pattern of its emergence is shown in Figure 6.

Figure 6: A natural pattern of emergence of intellectual entrepreneurship

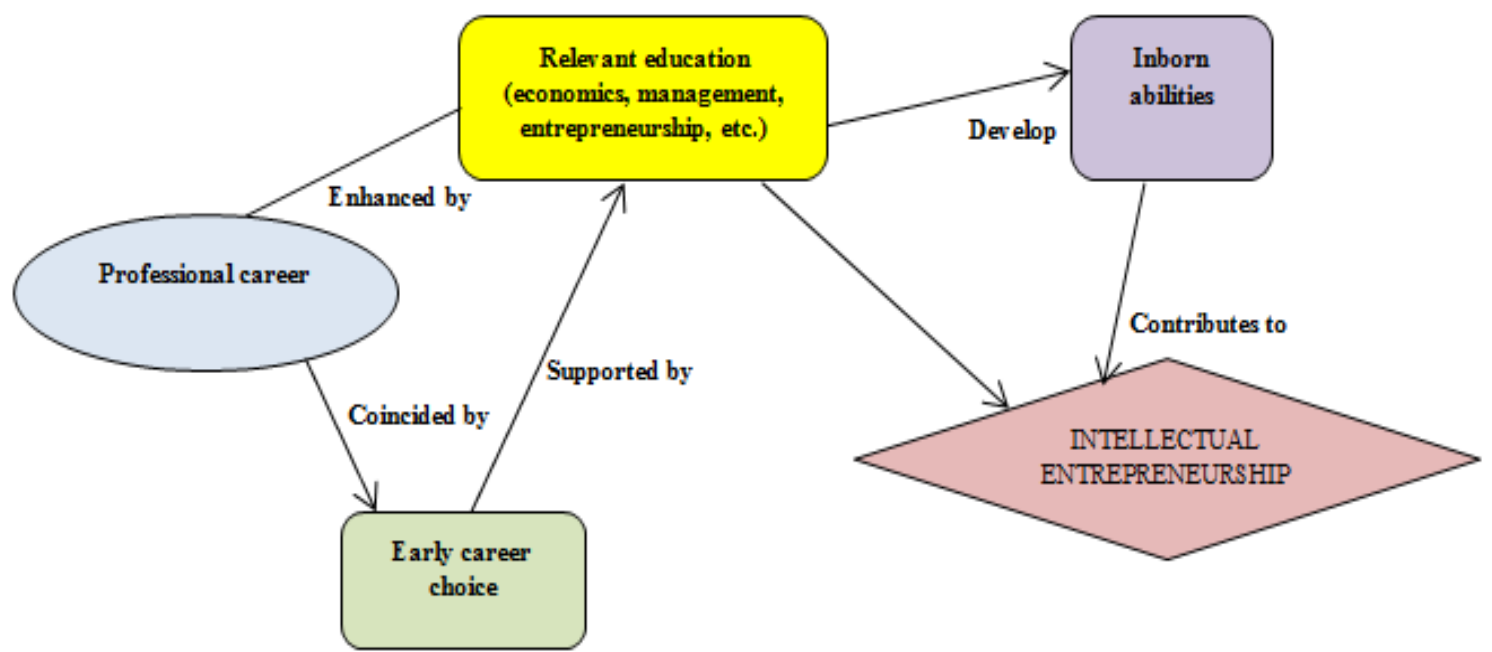

Source: Author

Natural ones are entrepreneurs whose professional career coincided with their early career choice, with their inborn abilities developed through education and professional training. They have chosen their education in the field of economics and management, which logically led them to entrepreneurship when the market environment allowed it. This group is characterized by their accumulative energy, i.e., accumulative effect of their education and professional experience, allowing surpassing general entrepreneurial standards.

The second group is constituted by successful entrepreneurs (Figure 7) whose professional career consisted of two interrelated stages: 1) obtaining a certain applied professional or vocational education (a musician, a hairdresser, or an engineer) and then 2) during their professional career, becoming dissatisfied with the existing way of doing business and consequently, realizing their own strategic vision either within the existing enterprise or, more frequently, establishing their own business, but in the same profession. 
Figure 7: Professional pattern of emergence of intellectual entrepreneurship

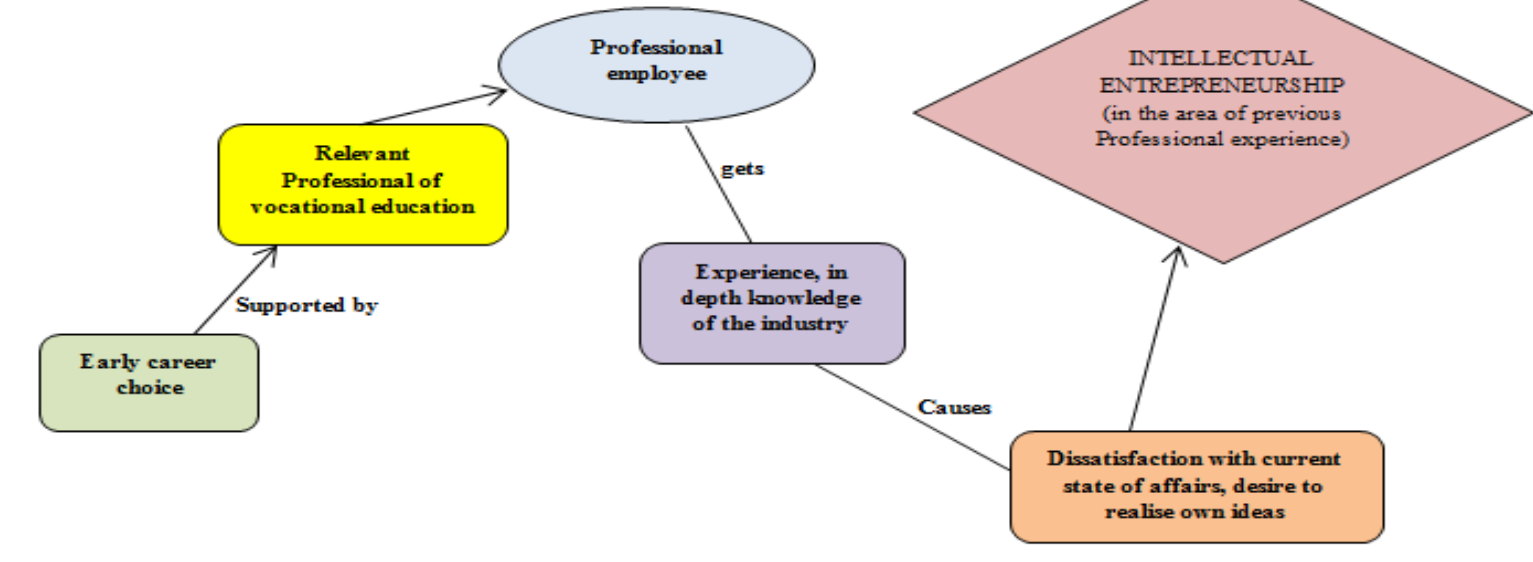

Source: Author

An example is a hairdresser who established his or her own chain of hairdressing salons. This is a pattern of transforming from a professional to an entrepreneur, and achieving the standards in the industry, which allows them to be included in the category of intellectual entrepreneurship. This realization of one's professional destiny is achieved without entrepreneurial education, and is based entirely on intellectual ability and knowledge of the profession. Entrepreneurship or management education, or both, then becomes the development tool. This pattern is called a "professional 'one (Figure 7).

The third group is labelled a displacement pattern (Figure 8), as it represents the situation where people become engaged in entrepreneurial activities after they have been displaced from their usual situation.

Figure 8: A displacement pattern of emergence of intellectual entrepreneurship

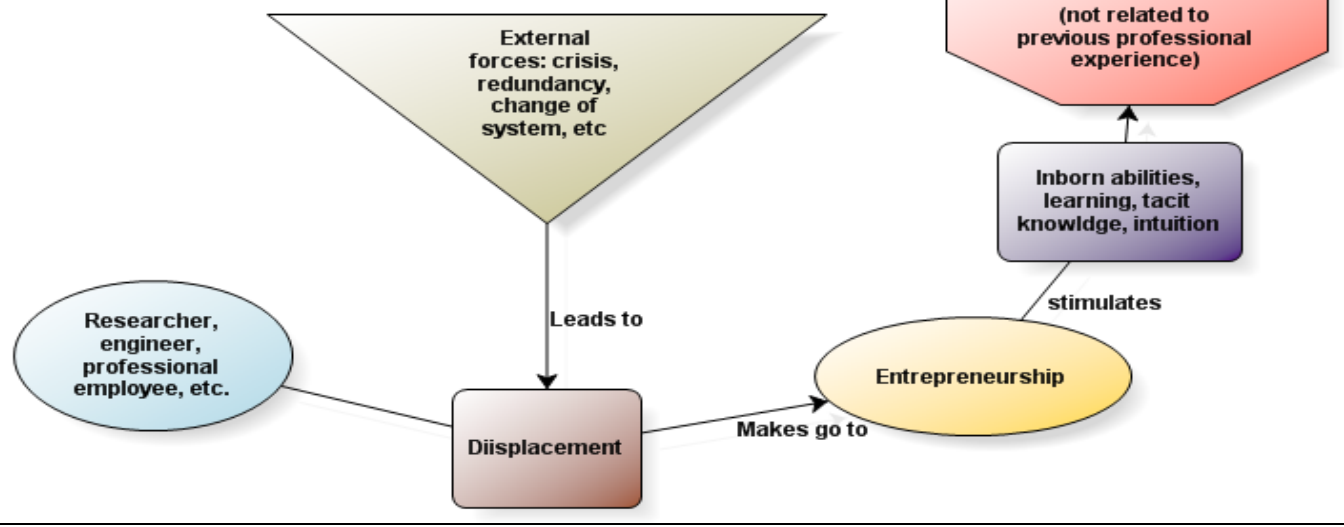

Source: Author

This type of intellectual entrepreneurship appears as a result of various crises, like collapse of the old system, bankruptcy, liquidation of an enterprise, or loss of finance. Such unnatural displacement places numerous people in the position of choosing their future labor activity outside their educational background or practical experience. Personal inner dissatisfaction, a desire to change a way of living, and increase personal well-being are the main drivers for these. Such people often excel in the spheres 
of entrepreneurial activity that was previously strange to them. This group of intellectual entrepreneurs is characterized by total professional reorientation and the exclusive use of their natural intellectual abilities in building their businesses.

As previously mentioned, these patterns are characteristics of a transitioned economy. An emerging pattern of intellectual entrepreneurship in a stable economic environment may be different and could be labelled as a 'hobby' (Figure 9).

Figure 9: A hobby pattern of emergence of intellectual entrepreneurship

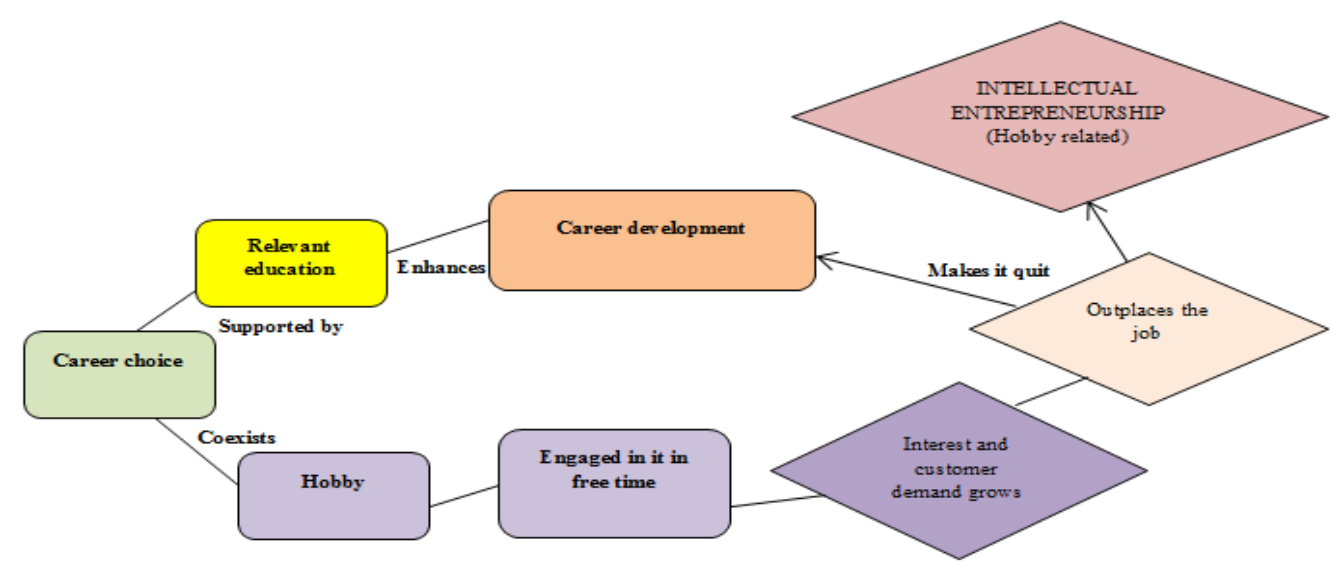

Source: Author

At one stage, a person who has chosen a career and starts a managerial career based on the education obtained, may also have a hobby on the side. First, one is engaged in a hobby in free time, but gradually the interest grows, the customer demands urge a person to devote more time to the endeavor, and one day they realize that it is no longer possible to combine it with a regular job, and thus, a choice is made. This often is the beginning of a new business that deviates a person from an earlier chosen career path.

\section{Conclusion}

The given paper contributes to the modern theory of entrepreneurship where the concept of intellectual entrepreneurship is used with different interpretations, and until recently had not been systematically studied. This study conceptualized the phenomenon of intellectual entrepreneurship, based on both secondary and field research, and provided a definition for intellectual entrepreneurship as being capitalization of knowledge in an innovative environment.

The emerging patterns of intellectual entrepreneurship in Latvia were identified during this research. This could form the foundation for practical application of the concepts in the training and education of future entrepreneurs; in specialized cross-disciplined programs for students studying entrepreneurship, economics, and business, and students from other disciplines; and thus increase the potential for developing intellectual entrepreneurs.

Although the study was limited to one country and qualitative studies are not generalizable in the statistical sense, the findings may be transferable (Marshall and Rossman, 1999). Possibly, the findings of the research could be applied to other countries that have experienced a similar transition, although the question remains as to whether it is a universal phenomenon or only relevant to postSoviet countries where the collapse of the 'old' system caused people to change their profession, to leave jobs that they liked, to forget their research aspirations, and to undertake the unknown.

\section{References}

Abosede, A. J \& Onakoya, A. B. (2013). Intellectual Entrepreneurship: Theories, Purpose and Challenges, International Journal of Business Administration 4.5 (2013): 30.

Ackoff, R. L. (1989). From Data to Wisdom. Journal of Applied Systems Analyses, p.16. 
Antal, A. B. (2004). The centrality of 'between' in intellectual entrepreneurship. In S. Kwiatkowski \& P. Houdayer (eds.) Knowledge café for intellectual entrepreneurship through or against institutions. Warsaw: Leon Kozminski Academy of Entrepreneurship and Management, pp. 27-52.

Beckman, G. \& Cherwitz, R. (2009). Intellectual Entrepreneurship: An Authentic Foundation for Higher Education Reform1. Planning for higher education 37.4 (Jul-Sep 2009): 27-36.

Central Statistical Bureau of Latvia. (2016, August 30). Retrieved from Central Statistical Bureau of Latvia: http://data.csb.gov.lv/pxweb/en/ekfin/ekfin_ikgad_ikp/IK10_0080.px/?rxid=cdcb978c-22b0-416a-aacc-aa650d3e2ce0

Cherwitz, R. \& Darwin, T. (2005). Crisis as Opportunity: An Entrepreneurial Approach to Productivity in Higher Education. in Miller,J and Groccia,J. (Eds) Enhancing Productivity in Higher Education, Anker Publishing Company, pp. 58-68 https://webspace.utexas.edu/cherwitz/www/articles/prod_univ.pdf

Cherwitz, R., \& Sullivan, C. (2002). 'Intellectual entrepreneurship. A vision for graduate education. Change, November/December, pp. 22-27.

Cherwitz, R. A. (2005). Diversifying graduate education: the promise of intellectual entrepreneurship. Journal of Hispanic Higher Education, vol. 4, No 1, pp.19-33. Sage publications.

Chia, R. (1996). Teaching paradigm shifting in management education: university business school and the entrepreneurial imagination, Journal of Management Studies, 33,4, pp. 409-428.

Edvinsson, L. (2003). IC entrepreneurship for knowledge capital as the new source of wealth of nations. In S. Kwiatkowski \& J. Sadlak (eds.) Knowledge café for intellectual entrepreneurship through higher education, Warsaw: Leon Kozminski Academy of Entrepreneurship and Management, pp. 21-41.

Etzioni, A. (1968) The active society. New York. Free press.

Gartner, W., Bird, B., \& Starr, J. (1992). Acting as if: differentiating entrepreneurial from organizational behaviour. Entrepreneurship Theory and Practice, 16 (3), pp.13-31.

Gold, S. (2003). Intellectual Entrepreneurship and the philosopher's stone. In S. Kwiatkowski \& J. Sadlak (eds.) Knowledge café for intellectual entrepreneurship through higher education. Warsaw: Leon Kozminski Academy of Entrepreneurship and Management, pp.123-140.

Invest in Sweden Agency. (2005). Retrieved from Invest in Sweden Agency: http://www.isa.se

Johannisson, B., Kwiatkowski, S. \& Dandridge, T. C. (1999). Intellectual entrepreneurship - emerging identity in a learning perspective, in S. Kwiatkowski and L. Edvinsson (eds) Knowledge Café for Intellectual Entrepreneurship, Warsaw: Leon Kozminski Academy of Entrepreneurship and Management, pp. 29-46.

Kirpalani, M. \& Nowak, A. Z. (2004). A. Intellectual international entrepreneurship from small and emerging markets: 'modern' industrial policy for Poland of clusters, networks, and born globals. In S. Kwiatkowski \& P. Houdayer (eds.) Knowledge café for intellectual entrepreneurship through or against institution. Warsaw: Leon Kozminski Academy of Entrepreneurship and Management, pp. 267-281.

Kirpalani, M. (2003). A model for development of intellectual entrepreneurs. In S. Kwiatkowski \& J. Sadlak (eds.) Knowledge café for intellectual entrepreneurship through higher education. Warsaw: Leon Kozminski Academy of Entrepreneurship and Management, pp.57-74.

Kwiatkowski, S. (1999). The intellectual entrepreneur (initial study), in S. Kwiatkowski \& L. Edvinsson (eds) Knowledge Café for Intellectual Entrepreneurship. Warsaw: Leon Kozminski Academy of Entrepreneurship and Management, pp.47-60. Kwiatkowski, S. (2001a). Join us for the knowledge café on intellectual entrepreneurship for sustainable development', in S. Kwiatkovski, \& C. Stowe (Eds) Knowledge Café for Intellectual Product and Intellectual Capital. Warsaw: Leon Kozminski Academy of Entrepreneurship and Management, pp.7-23.

Kwiatkowski, S. (2001b). Intellectual entrepreneurship - a feature of knowledge economy in transition. In T. Paszynski (Ed.) Vision and Reality. Warsaw: Leon Kozminski Academy of Entrepreneurship and Management, pp. 143-158.

Marshall, C., \& Rossman, G. (1999). Designing qualitative research ( $3^{\text {nd }}$ ed.). Thousand Sage publications.

Neuman, W. L. (2003). Social Research methods. Qualitative and quantitative approaches $\left(5^{\text {th }}\right.$ ed.). Pearson education.

Mavridis, D. (2011). The Intellectual Entrepreneur - Vision or Fiction. Proceedings of the 4th International Conference, researchgate.net

Sharif, N. M. (2004). Intellectual entrepreneurship for economic leapfrogging in developing countries: technology literacy as the launching pad. In S. Kwiatkowski \& P. Houdayer (eds.) Knowledge café for intellectual entrepreneurship through or against institution, Warsaw: Leon Kozminski Academy of Entrepreneurship and Management, pp. 283-312.

Stowe, C. (2001). Intellectual entrepreneurship - the conversion of intellectual capital into financial capital', in S.

Kwiatkovski. \& C. Stowe (Eds) Knowledge Café for Intellectual Product and Intellectual Capital. Warsaw: Leon Kozminski Academy of Entrepreneurship and Management, pp.65-90.

Stowe, C. (1999). On developing intellectual capitalists. In S. Kwiatkowski \& L. Edvinsson (eds.) Knowledge café for intellectual entrepreneurship. Warsaw: Leon Kozminski Academy of Entrepreneurship and Management, pp. 129-140.

Stowe, C. (2004). Exploring institutional and informational barriers to intellectual entrepreneurship. In S. Kwiatkowski \& P. Houdayer (eds.) Knowledge café for intellectual entrepreneurship through or against institutions. Warsaw: Leon Kozminski Academy of Entrepreneurship and Management, pp. 313-349.

Yin (2003). Case study research Design and Methods. Third edition. Applied Social Research Methods Series, Volume 5, Sage publications. 